\title{
EbolaTracks: an automated SMS system for monitoring persons potentially exposed to Ebola virus disease
}

L E Tracey (lauren.tracey@health.wa.gov.au) ${ }^{1}$, A K Regan¹, P K Armstrong ${ }^{1}$, G K Dowse1, P V Effler ${ }^{1}$

1. Communicable Disease Control Directorate, Department of Health, Perth, Western Australia, Australia

Citation style for this article:

Tracey LE, Regan AK, Armstrong PK, Dowse GK, Effler PV. EbolaTracks: an automated SMS system for monitoring persons potentially exposed to Ebola virus disease. Euro Surveill. 2015;20(1):pii=20999. Available online: http://www.eurosurveillance.org/ViewArticle.aspx?Articleld=20999

Article submitted on 16 December 2014 / published on 08 January 2015

We report development and implementation of a short message service (SMS)-based system to facilitate active monitoring of persons potentially exposed to Ebola virus disease (EVD), whether returning from EVD-affected countries, or contacts of local cases, should they occur. The system solicits information on symptoms and temperature twice daily. We demonstrated proof-of-concept; however this system would likely be even more useful where there are many local contacts to confirmed EVD cases or travellers from EVD-affected countries.

\section{Background}

The 2014-2015 Ebola virus disease (EVD) outbreak in West Africa is the largest in history, with widespread and ongoing transmission occurring in Guinea, Liberia, and Sierra Leone [1]. In addition, four countries (Mali, Nigeria, Senegal, and the United States of America (US)) have had EVD cases imported from West Africa. Moreover aid and healthcare workers (HCW) who developed EVD in West Africa have been evacuated by air for treatment in the US and several European countries [2]. One or more secondary cases have occurred in Mali, Nigeria, Spain and the US [2]. Internationally, public health authorities recommend surveillance of contacts of people with Ebola virus infection for 21 days following their last potential exposure so they can be promptly isolated and treated if they develop illness, minimising opportunities for further spread [3-6]. Depending on an individual risk assessment, and with some variation between countries, passive or active monitoring is recommended for HCWs, household and community contacts of persons with EVD, and in some instances, for travellers from EVD-affected countries irrespective of a specific exposure history.

Limited experience outside West Africa to date demonstrates that monitoring contacts of persons with EVD requires 'substantial time, resources, and coordination between local health jurisdictions' and that the number of persons requiring follow-up can quickly escalate [7]. Short message services (SMS) technology has been effectively used in a variety of public health and medical monitoring programmes [8-13]. Given our prior success in using SMS to conduct vaccine safety surveillance [14], we sought to develop an SMS-based system to streamline active monitoring of persons potentially exposed to EVD. Here we describe an automated SMS system implemented by the Department of Health in Western Australia (WA Health) to actively monitor travellers returning from EVD-affected countries, and contacts of any locally diagnosed EVD cases in WA (should the need arise).

\section{Description of the system}

The 'EbolaTracks SMS system' is designed to facilitate active monitoring of EVD contacts for 21 days following their last possible exposure to Ebola virus. As there have been no EVD cases diagnosed in WA, the system has thus far focused on monitoring persons who have travelled from the EVD-affected countries Guinea, Liberia, and Sierra Leone. These travellers, potentially exposed to EVD, are identified by federal authorities at Perth International Airport and their contact details and travel history are recorded. WA Health then provides these individuals with an EbolaTracks monitoring pack, which includes information about EVD, an explanation of the purpose of the system and its operation, a digital thermometer, instructions on how to take and report temperature by SMS to WA Health, and a mobile phone with one month's credit if they do not have their own. Based on reported exposures, travellers (or potentially local contacts) are classified as casual, low, or high risk, according to Australian criteria [6]. Participants are also categorised according to exposure type as HCW, household contacts, or 'other', which includes travellers from EVD-affected countries and local contacts in settings such as public transport. Those enrolled into the system are either manually entered as individual records or batch imported via a spreadsheet (in the case of larger volumes). The enrolment details include everything captured on the enrolment form (i.e. demographics, date of last possible exposure, contact details and information about risk).

The EbolaTracks software was developed using the database programme FileMaker and runs on the Microsoft Windows 7 operating system. The SMS 
functionality utilises an SMS gateway to send and receive messages via mobile telephone networks. Persons under surveillance are requested to take their temperature twice daily between the hours of 8 and 9AM and again between 5 and 6PM.

EbolaTracks participants are contacted twice daily by SMS, at 9AM and 6PM respectively. At each of those times, the system sends two consecutive SMSs. The first SMS asks if the participant is feeling unwell and requests a ' $Y$ ' (for yes) or ' $N$ ' (for no) response by SMS. Should the participant's response differ from the ' $Y$ ' or ' $N$ ' format requested, the software can convert ca 50 commonly used variations, such as 'Yes' or 'No', and can appropriately parse answers that include spaces and/or punctuation. Following the first SMS and response, a second SMS asks the participant to report their temperature, recorded in degree Celsius (Figure). In interpreting the participant's SMS response with their temperature, the software will filter out all characters except numbers, full stops and commas.

\section{FIGURE}

An example of the text messages sent from EbolaTracks each morning with responses from a fictitious participant

Good morning. This is a message from the WA Department of Health for John Doe. Are you feeling unwell this morning? Please reply $\mathrm{Y}$ or $\mathrm{N}$ only.
TABLE

Individuals undergoing 21 day health monitoring using EbolaTracks, Western Australia, 21 November 2014-5 January $2015(n=22)$

\begin{tabular}{|l|c|c|c|c|}
\hline Residence & $\begin{array}{c}\text { Date of last } \\
\text { potential } \\
\text { exposure to } \\
\text { Ebola virus }\end{array}$ & $\begin{array}{c}\text { Monitoring } \\
\text { completion } \\
\text { date }^{\text {b }}\end{array}$ & $\begin{array}{c}\text { Risk } \\
\text { type[6] }\end{array}$ & $\begin{array}{c}\text { Risk Level } \\
\text { [6] }\end{array}$ \\
\hline Urban & $16 / 11 / 2014$ & $06 / 12 / 2014$ & Other & Casual \\
\hline Urban & $19 / 11 / 2014$ & $10 / 12 / 2014$ & $\begin{array}{c}\text { Healthcare } \\
\text { worker }\end{array}$ & Low \\
\hline Rural & $29 / 11 / 2014$ & $19 / 12 / 2014$ & Other & Casual \\
\hline Urban & $29 / 11 / 2014$ & $19 / 12 / 2014$ & Other & Casual \\
\hline Urban & $29 / 11 / 2014$ & $19 / 12 / 2014$ & Other & Casual \\
\hline Urban & $30 / 11 / 2014$ & $20 / 12 / 2014$ & $\begin{array}{c}\text { Healthcare } \\
\text { Worker }\end{array}$ & Low \\
\hline Urban & $01 / 12 / 2014$ & $21 / 12 / 2014$ & Other & Casual \\
\hline Urban & $03 / 12 / 2014$ & $23 / 12 / 2014$ & Other & Casual \\
\hline Urban & $06 / 12 / 2014$ & $27 / 12 / 2014$ & Other & Casual \\
\hline Urban & $10 / 12 / 2014$ & $30 / 12 / 2014$ & Other & Casual \\
\hline Rural & $10 / 12 / 2014$ & $17 / 12 / 2014$ & Other & Casual \\
\hline Rural & $10 / 12 / 2014$ & $30 / 12 / 2014$ & Other & Casual \\
\hline Urban & $16 / 12 / 2014$ & $04 / 01 / 2015$ & Other & Casual \\
\hline Urban & $17 / 12 / 2014$ & $02 / 01 / 2015$ & Other & Casual \\
\hline Urban & $18 / 12 / 2014$ & $06 / 01 / 2015$ & Other & Casual \\
\hline Urban & $18 / 12 / 2014$ & $08 / 01 / 2015$ & Other & Casual \\
\hline Urban & $18 / 12 / 2014$ & $08 / 01 / 2015$ & Other & Casual \\
\hline Urban & $18 / 12 / 2014$ & $08 / 01 / 2015$ & Other & Casual \\
\hline Urban & $19 / 12 / 2014$ & $09 / 01 / 2015$ & Other & Casual \\
\hline Urban & $21 / 12 / 2014$ & $11 / 01 / 2015$ & Other & Casual \\
\hline Rural & $21 / 12 / 2014$ & $11 / 01 / 2015$ & Other & Casual \\
\hline Urban & $25 / 12 / 2014$ & $15 / 01 / 2015$ & Other & Casual \\
\hline
\end{tabular}

Urban means residing within a greater metropolitan area, with access to a tertiary hospital with capacity to test for and treat patients with Ebola virus disease; rural means residing outside a metropolitan area.

b The monitoring completion date indicates either the end of the $\mathbf{2 1}$ day monitoring period or the day the individual left Western Australia.

For any participants who report feeling unwell or a temperature $\geq 37.5^{\circ} \mathrm{C}$, EbolaTracks automatically sends both an SMS and an email alert to an on-call medical officer, who then telephones the individual to assess their condition and determine appropriate management. In addition, if an individual does not respond within an hour, EbolaTracks generates an SMS and email alert to the on-call officer, who then contacts the person to check their condition and to ensure that they are monitoring their temperature. Any SMS responses that cannot be interpreted by the programme are considered non-responses during automated processing and the on-call officer is notified. The on-call officer can review these responses, interpret and manipulate them manually, or may contact the participant if further clarification is needed.

Once enrolled, the automated system will send and receive SMS messages for all active records. Each 
participant is included in the process until they reach 21 days after the date of last possible exposure to EVD or they depart WA.

Users of the software have the opportunity to monitor the automated process running in real-time and view the responses as they are received. All historical responses can be reviewed at any time. If no alerts are generated, it means all people currently under surveillance have answered both messages and all have reported being well and afebrile, and no further action is required.

The database used to send and receive SMS messages to/from persons who have been potentially exposed to EVD is maintained on a password protected/secure server within the WA Health Department. Any mobile telephone numbers used are verified with the contact before enrolment in EbolaTracks, and the ensuing SMS communications are subject to the same level of security as voice calls on commercial telephone networks.

\section{Experience using EbolaTracks}

EbolaTracks became operational on 21 November 2014 . Twenty-two individuals who have arrived in WA from EVD-affected countries have been enrolled as of 5 January 2015 and 14 of these participants have successfully completed active monitoring (Table). The average age of participants was 46 years (range: $28-68$ years; 18 men and 4 women), whereby three returned from Guinea, three from Liberia, and 16 from Sierra Leone.

To date, the system has sent a total of 1,108 messages soliciting symptom information, of which 1,008 (91\%) received a return SMS; the remaining 100 outgoing EbolaTracks messages received no reply or were uninterpretable and required telephone follow-up by the Department of Health to confirm that the participants remained well and afebrile. Of the 1,008 responses received, 1,007 replies indicated the individuals were well and afebrile; one participant reported an elevated temperature. At the end of December, this non-HCW who had returned from one of the EVD-affected countries six days prior, replied by SMS with a temperature of $37.7^{\circ} \mathrm{C}$. This response generated an alert to the oncall medical officer who subsequently interviewed the traveller. Repeated measurements confirmed a lowgrade fever but the individual was otherwise asymptomatic at the time of the call. They were advised to stay at home until further notice, and a programme of regular follow-up was established which included more frequent temperature monitoring and regular contact with the medical officer. The low-grade fever resolved within a day and the individual remains well.

\section{Discussion}

Interrupting chains of human-to-human transmission is the highest priority for preventing the spread of EVD. Early identification, isolation and testing of suspected cases is essential, both for providing optimal care to patients and for preventing further transmission [4].
Our experience suggests that an SMS-based symptom monitoring system can assist in these goals by facilitating active monitoring of potentially exposed individuals while conserving staff resources. In addition, we found EbolaTracks was relatively straight-forward to develop and implement, built over a 19 day period using a contracted systems designer for a cost of approximately $€ 17,000$.

A strength of EbolaTracks is that this system can accommodate large numbers of both potentially exposed incoming travellers from EVD-affected countries and HCWs, household and community contacts exposed to a domestic EVD case. Furthermore, it is easily scalable; while we have demonstrated proofof-concept in WA, this SMS-based monitoring would likely be even more useful where there are a large volume of contacts to follow-up, for example, in European countries or the US which receive many more travellers from EVD-affected areas than does Australia - or when actively monitoring numerous healthcare and community contacts of an imported or local secondary case. By reducing the resources required to perform active monitoring of contacts, SMS-based systems permit expansion of active monitoring to situations now reliant on passive self-monitoring, thus improving public confidence in EVD control strategies. In our setting at least, an additional positive attribute is that the SMS approach is highly acceptable to participants as it provides potential benefits to them, with minimum imposition or inconvenience.

The potential value of using SMS systems for active monitoring of Ebola contacts is not limited to industrialised countries; mobile phone use is widespread in many parts of Africa and any country with a moderate to high level of mobile phone coverage ought to be able to benefit from this approach [15]. SMS has already successfully been integrated into the public health response to EVD in Nigeria and Senegal. In Nigeria, HCW used a real-time reporting application to upload laboratory test results and receive SMS information on individuals being monitored for EVD symptoms [16], and the United Nations Children's Fund (UNICEF) developed a cascade SMS system to educate people about Ebola virus transmission and prevention [17]. In Senegal, the Ministry of Health sent 4 million SMS messages to the public, warning of the dangers of EVD and how to prevent it as part of a coordinated public awareness campaign [18]. These examples highlight that SMS has already been successfully integrated into the public health response to the EVD outbreak, and our application extends this to automated, active monitoring of persons potentially exposed to EVD.

There are limitations of the SMS-based approach to monitoring EVD contacts. First, SMS monitoring cannot supplant the potential advantages of direct visual inspection recommended for high risk contacts as the lack of fever and illness is not independently verified. Thus, subject to resources, it may be preferable to 
monitor persons at very high risk in-person, or potentially using video calls. Second, the system must be adequately explained to participants so that the number of uninterpretable responses and delayed responses requiring follow-up can be minimised. Third, not everybody will have a mobile phone or be able to use one; in our setting, we will provide an inexpensive mobile phone with time-limited credit to contacts who do not already have one, but so far this has not been necessary. Finally, we must acknowledge that some contacts to Ebola cases may be disinclined to selfreport illness if they subsequently become unwell. We believe, however, that disincentives to self-reporting can be overcome by ensuring timely access to appropriate diagnostics and prompt provision of high quality medical care, should it be necessary.

As long as the current epidemic continues in West Africa, active monitoring of individuals travelling from EVD-affected countries, particularly those with documented exposures (such as HCW), remains a cornerstone of public health strategies to facilitate early identification of imported cases and prevent local transmission, in both developing and developed countries [19]. In WA, EbolaTracks has proven useful and efficient for monitoring travellers arriving from West Africa. While the future course of the current epidemic is unknown, large numbers of potential exposures stemming from air travel, use of public transport, and healthcare provided to an imported case are not inconceivable, as has occurred in the US [7]. In our assessment, SMS-based fever and symptom monitoring systems could be valuable tools for implementing large-scale active monitoring of contacts exposed to EVD and other serious infectious diseases.

\section{Acknowledgments}

The authors would like to acknowledge the work of Ian Peters from Datavation for the programming and development of the EbolaTracks system.

\section{Conflict of interest}

None declared.

\section{Authors' contributions}

PE conceived the concept. LT and AR worked with the programmer on the system development and performed data collection and analysis. All authors contributed to development of system methods and protocols. All authors discussed the results, edited and commented on the manuscript draft. All authors read and approved the final manuscript.

\section{References}

1. World Health Organisation (WHO). Ebola Response Roadmap. Geneva:WHO;Aug 2014. [Accessed 10 Dec 2014]. Available from: http://apps.who.int/iris/bitstream/10665/131596/1/ EbolaResponseRoadmap.pdf?ua=1

2. World Health Organisation (WHO). Ebola Response Roadmap Situation Report 10 December 2014. Geneva:WHO; Dec 2014.
[Accessed 11 Dec 2014]. Available from: http://apps.who.int/ iris/bitstream/10665/145198/1/roadmapsitrep_10Dec2014_ eng.pdf

3. Centers for Disease Prevention and Control (CDC). Interim U.S. Guidance for Monitoring and Movement of Persons with Potential Ebola Virus Exposure. Atlanta:CDC. [Accessed 6 Dec 2014]. Available from: http://www.cdc.gov/vhf/ebola/ exposure/monitoring-and-movement-of-persons-withexposure.html

4. European Centre for Disease Prevention and Control (ECDC). Public health management of persons having had contact with Ebola virus disease cases in the EU. Stockholm: ECDC; Oct 2014. [Accessed 1 Dec 2014]. Available from: http://ecdc. europa.eu/en/publications/Publications/ebola-public-healthcontact-management.pdf

5. World Health Organisation (WHO). Contact tracing during an outbreak of Ebola virus disease. 2014. Geneva:WHO; Sep 2014 [Accessed 10 Dec 2014]. Available from: http://www.who.int/ csr/resources/publications/ebola/contact-tracing-duringoutbreak-of-ebola.pdf?ua=1

6. Communicable Diseases Network Australia (CDNA). Ebola Virus Disease CDNA National Guidelines for Public Health Units. Canberra: Department of Health. [Accessed 6 Dec 2014]. Available from: http://health.gov.au/internet/main/publishing. nsf/Content/ohp-ebola.htm/\$File/EVD-SoNG.pdf

7. McCarty CL, Basler C, Karwowski M, Erme M, Nixon G, Kippes $C$, et al. Response to Importation of a Case of Ebola Virus Disease - Ohio, October 2014. MMWR Morb Mortal Wkly Rep. 2014;63(46):1089-91.. PMID: 25412070

8. Rajatonirina S, Heraud JM, Randrianasolo L, Orelle A, Razanajatovo NH, Raoelina YN, et al. Short message service sentinel surveillance of influenza-like illness in Madagascar, 2008-2012. Bull World Health Organ. 2012;90(5):385-9. http:// dx.doi.org/10.2471/BLT.11.097816 PMID:22589573

9. Lim MS, Hocking JS, Hellard ME, Aitken CK. SMS STI: a review of the uses of mobile phone text messaging in sexual health. Int J STD AIDS. 2008;19(5):287-90. http://dx.doi.org/10.1258/ ijsa.2007.007264 PMID:18482956

10. Freifeld CC, Chunara R, Mekaru SR, Chan EH, Kass-Hout T, Ayala lacucci A, et al. Participatory epidemiology: use of mobile phones for community-based health reporting. PLoS Med. 2010;7(12):e1000376. http://dx.doi.org/10.1371/journal. pmed.1000376 PMID:21151888

11. Tamrat T, Kachnowski S. Special delivery: an analysis of mHealth in maternal and newborn health programs and their outcomes around the world. Matern Child Health J. 2012;16(5):1092-101. http://dx.doi.org/10.1007/s10995-0110836-3 PMID:21688111

12. Zhang Y, Chen L, van Velthoven MH, Wang W, Liu L, Du X, et al. mHealth Series: Measuring maternal newborn and child health coverage by text messaging - a county-level model for China. J Glob Health. 2013;3(2):020402. http://dx.doi.org/10.7189/ jogh.03.020402 PMID:24363920

13. Haberer JE, Kiwanuka J, Nansera D, Wilson IB, Bangsberg DR. Challenges in using mobile phones for collection of antiretroviral therapy adherence data in a resource-limited setting. AIDS Behav. 2010;14(6):1294-301. http://dx.doi. org/10.1007/s10461-010-9720-1 PMID:20532605

14. Leeb A, Regan AK, Peters IJ, Leeb C, Leeb G, Effler PV. Using automated text messages to monitor adverse events following immunisation in general practice. Med J Aust. 2014;200(7):4168. http://dx.doi.org/10.5694/mja13.11166 PMID:24794676

15. Aker JC, Mbiti IM. Mobile phones and economic development in Africa. CGD Working Paper 211. Washington DC: Center for Global Development; Jun 2010. Available from: http://www. cgdev.org/files/1424175_file_Aker_Mobile_wp211_FINAL.pdf

16. mHealthNews. WHO credits mHealth app with helping Nigeria get rid of Ebola. [Accessed 6 Dec 2014]. Available from: http://www.mhealthnews.com/news/ who-credits-mhealth-app-helping-nigeria-get-rid-ebola

17. Njoku G. In Nigeria, texting to prevent Ebola. Abuja: United Nations Children's Fund. [Accessed 30 Nov 2014]. Available from: http://www.unicef.org/infobycountry/nigeria_76251.html

18. World Health Organisation (WHO). Government of Senegal boosts Ebola awareness through SMS campaign. Geneva: WHO; Nov 2014.[Accessed 30 Nov 2014]. Available from: http:// www.who.int/features/2014/senegal-ebola-sms/en/

19. European Centre for Disease Prevention and Control (ECDC). Outbreak of Ebola virus disease in West Africa. Sixth update, 13 October 2014. Stockholm: ECDC;2014. Available from: http://www.ecdc.europa.eu/en/publications/Publications/ ebola-sierra-leone-liberia-guinea-nigeria-spain-14-10-2014risk-assessment.pdf 